\title{
MARINE ECOSYSTEM ASSESSMENT: PAST, PRESENT AND FUTURE ATTEMPTS WITH EMPHASIS ON THE EASTERN SCOTIAN SHELF
}

\author{
KENNETH T. FRANK*, JAE S. CHOI and BRIAN PETRIE \\ Ocean Sciences Division, Science Branch \\ Department of Fisheries and Oceans, Maritimes Region \\ Bedford Institute of Oceanography \\ PO Box 1006 \\ Dartmouth, Nova Scotia B2Y $4 A 2$
}

The collapse of major fish stocks around the world, their failure to recover even after the cessation of fishing, and the perceived deficiencies in single species fisheries management has resulted in an intensified interest in the study of whole systems. Assessment of ecosystems is a relatively new phenomenon and represents a significant departure from the past focus on individual ecosystem components such as individual, commerciallyexploited stocks of fish and invertebrates in isolation from their physical, chemical and biological environment. A report entitled "State of the Eastern Scotian Shelf Ecosystem" was completed recently and some of its main findings form the body of this paper. The analysis focused on more than 60 data series, most extending back to at least 1970 , associated with three categories of variables: biotic, abiotic and human. Biotic variables included the abundance, distribution and composition of finfish and invertebrates, phyto- and zooplankton, and marine mammals. Abiotic variables included oceanic and atmospheric data that specify ocean climate conditions. Human variables ranged from fisheries landings and revenue, activities associated with oil and gas development and contaminants. By examining temporal variations in the data, an assessment was made of the current status of the ecosystem relative to its past state.

L'effondrement de stocks de poissons importants partout dans le monde, l'incapacité de ces stocks à se rétablir même après l'arrêt de toute activité de pêche et les lacunes perçues dans la gestion des pêches axées sur une espèce ont donné lieu à une hausse de l'intérêt pour les études écosystémiques. L'évaluation des écosystèmes est un domaine relativement nouveau et constitue un changement d'orientation considérable par rapport à l'importance accordée par le passé aux composantes individuelles des écosystèmes, comme les stocks de poissons et d'invertébrés particuliers exploités à des fins commerciales sans tenir compte de leur milieu physique, chimique et biologique. Un rapport intitulé "État de l'écosystème de l'est du plateau néo-écossais » a été parachevé récemment, et certaines des principales conclusions présentées dans ce rapport constituent le corps du présent document. L'analyse a porté sur trois catégories de facteurs (biotiques, abiotiques et anthropiques) dans plus de 60 jeux de données, la plupart remontant au minimum à 1970. Les variables biotiques sont notamment l'abondance et la répartition des poissons, des invertébrés, du phytoplancton, du zooplancton et des mammifères marins, ainsi que la composition de leurs communautés. Les variables abiotiques comprennent les données océaniques et atmosphériques qui permettent de comprendre le climat océanique. Les facteurs anthropiques englobent les prises de poisson, les revenus de pêche, les activités liées à la mise en valeur du pétrole et du gaz et les contaminants. L'examen des tendances temporelles dans les données a permis d'évaluer l'état actuel de l'écosystème par rapport à son état antérieur.

* Author to whom correspondence should be addressed

E-mail: frankk@mar.dfo-mpo.gc.ca 


\section{INTRODUCTION}

Is it possible to assess the status of large, complexly inter-woven, multidimensional and multi-causal systems? What pre-conditions are required for such an assessment to be successful and useful? These are the main issues that we wish to examine in light of a recent attempt by the Canadian Department of Fisheries and Oceans (DFO) to produce such an integrated assessment of the status of a large ocean area, the eastern Scotian Shelf ecosystem.

What exactly is meant by "assessment"? To assess generally refers to an evaluation of the magnitude and quality of some object. The word frequently is used in the context of economics (e.g., for the purposes of valuation and taxation) and medicine (e.g., an assessment of the health of an individual). In the ecological context, both connotations of the word are used. The economic connotation is represented by an evolving field of what is known as "ecological-economics" where the focus is on evaluating the monetary value of various ecological structures and functions (e.g., What is the monetary value of clean-air or the function of forests in maintaining the global carbon cycle for the purposes of a "carbon" tax, or some undiscovered plant's disease prevention capacity). The medical connotation is represented by another recently evolving field that is concerned with "ecological health" (e.g., Are there indicators of ecosystem health just as there are indicators of human physiological, psychological or even spiritual health, or distress?). It is not yet clear which of these two models, ecological economics or ecological health, is more appropriate in an ecological context. In fact, both models may be necessary for the further development of ecological assessments as the tension between the economic model, which is decidedly more reductionist in perspective, and the medical model, which is more synthetic, may foster creativity and deeper knowledge of ecological assessment.

Why the desire to assess the status of ecosystems? With the ever-increasing human modification of ecosystems, the public consciousness of their dependence upon the ecosystems in which they live has become more widespread and vocal. The social, economic and political consequences of environmental and ecological disasters are proving to be tremendous forces that are difficult to ignore because of their direct and indirect influences upon our own health and wealth (e.g., oil spills, groundwater contamination, food contamination and bioaccumulation of toxic chemicals, radiation poisoning, invasive species, fisheries collapses, agricultural collapse, rapid climate change). In marine systems, the collapse of major fish stocks around the world, their failure to recover even after the cessation of fishing, and the perceived deficiencies in single species fisheries management has resulted in an intensified interest in the study of whole systems. The issue is: will continued or increased human modification and exploitation of the ecosystem or part thereof, result in some calamity that will damage our health and wealth? This question stands behind the popular call for sustainability and minimal ecological footprints or impacts. 
While the demand for some comprehensive and comprehensible assessment is ever-increasing, the mechanisms by which such demands may be met are lacking. The scientists that are called upon to provide such assessments work in a social, political and economic atmosphere that fosters extreme specialization. For example, most marine scientists study particular aspects of the biology, chemistry or physics of the ocean. Among each of these broad categories there is a finer degree of specialization so that within the realm of marine biology, for example, individuals focus on fish, plankton, whales and so on. The division continues, often to the level of functional grouping of species such as groundfish, pelagic fishes (either large or small ones such as tuna and swordfish versus mackerel and herring), zooplankton, phytoplankton and benthic invertebrates to name just a few. In government laboratories further refinement occurs with specialists for individual species, particularly among those species that are commercially exploited. The need to provide scientific advice to fisheries managers, participation in species-specific working groups, symposia and scientific journals tend to reinforce the commitment to research at such a specialized level.

This tendency to hyper-specialization is further exacerbated by the natural complexity of ecosystems. There are many types of organisms that each behave in complex and interdependent ways. This complexity in behavior becomes more apparent the more a particular organism (singular) is studied. This onslaught of information makes its synthesis into an integrated whole all the more challenging. To satisfy the demands of some scientists for reliable and complete information to understand, describe and provide assessments of an ecosystem would require resources beyond what could reasonably be expected. Further, as the total resources available is a strong limiting constraint, there is an inverse relationship between spatial and temporal coverage in research and in monitoring programs - more research, less monitoring and vice versa. With even the simplest of assessments many assumptions are required thereby reducing the reliability of any extrapolation.

Even if near-perfect information were somehow available to assess the status of an ecosystem, the science of "complexity" and non-linear dynamical systems theory of more recent years indicate that there is a rapid diminishing of returns in understanding a complex system for each bit of information gained. Even after years of focused research of the much "simpler" and better understood climatological processes, large uncertainties exist with even the best forecasts. What then are the chances for a biologist to produce an assessment of a hyper-complex ecosystem with any real rigor, reliability or authority?

It is not surprising, therefore, that there have been few attempts to assess either communities of organisms or entire ecosystems. Some attempts have been made by pioneering ecologists such as Raymond Lindeman (1942), Eugene Odum (1968, 1969), Howard Odum (1971, 1983), Bernard Patten (1971, 1982), David Schindler (1990) and John Steele (1985) as well as 
through large international efforts such as the International Biological Program, but these attempts have always fallen short, because of the unforgiving complexity of natural ecosystems and limited funding (the agencies may have been strongly motivated to fund but did not have the means to do so). Recently through the activities of the Smithsonian Institution and numerous co-operating agencies, long-term monitoring of large areas has been established throughout the world [Decision Support System for Sustainable Ecosystem Management in Atlantic Rain Forest Rural Areas (ECOMAN)] in an attempt to consolidate existing observations and to extend them in time through additional measurements. ECOMAN has focused mostly on the terrestrial environment. In aquatic systems, long-term freshwater studies have been and continue to be a field of active research led by such notables as Henry Regier (1973, 1996), RA Vollenweider (1976), and David Schindler (1990). In the much larger marine systems, considerably less has been done, but the situation is changing, particularly due to the efforts of Kenneth Sherman and his Large Marine Ecosystem (LME) initiative that began in the late 1980s. His approach has been to assess the ecological state of LMEs using a case-study approach to examine the causes and effects of environmental and human-induced changes of ecosystem productivity (e.g. see Sherman \& Skjoldal 2002). While the initiative has met with mixed success it has stimulated the assembly and analysis of a broad base of environmental data.

Over 30 years ago, Canadian government laboratories made a commitment to long term and large scale monitoring of various components of the marine ecosystem using standardized methods of sampling. The availability of this high-quality information has allowed a first attempt at a comprehensive, integrated assessment of the current status of a large ocean area or ecosystem under Canadian jurisdiction. In the past, the focus has been on the examination of individual ecosystem components such as individual, commercially-exploited stocks of fish and invertebrates, the physical and biological environment, and various status reports (e.g. contaminants). A report entitled "State of the Eastern Scotian Shelf Ecosystem" (DFO 2003) was completed by a dedicated team of specialists and synthesizes much of the information available for the area. Its findings form the body of the remainder of this paper.

The State of the Ecosystem report was a product of a working group that compiled and analyzed various data relevant to the evaluation of the eastern Scotian Shelf ecosystem. The analysis focused on more than 60 data series, most extending back to at least 1970, associated with three categories of variables: biotic, abiotic and human. Biotic variables included the abundance, distribution and composition of finfish and invertebrates, phyto- and zooplankton, and marine mammals. Abiotic variables included oceanic and atmospheric data that specified ocean climate conditions. Human variables ranged from fishery landings and revenue to activities associated with oil and gas development and contaminants. By examining temporal variations of the data, an assessment was made of the current status of the ecosystem relative to its past. 


\section{METHODS}

\section{Study area}

The Eastern Scotian Shelf (ESS), comprising Northwest Atlantic Fisheries Organization (NAFO) Division 4VW, is a large geographic area $(\sim 108,000$ $\mathrm{km}^{2}$ ) supporting a wide range of uses such as fisheries, oil and gas exploration and development, and shipping (Fig 1). It is currently the focus of the development of an integrated management plan with the intent to harmonize the conduct of the various ocean activities within it (referred to as ESSIM: Eastern Scotian Shelf Integrated Management). The ESS consists of a series of outer shallow banks and inner basins separated by gullies and channels. The mean surface circulation is dominated by southwestward flow, much of which originates from the Gulf of St. Lawrence with anticyclonic (clockwise) circulation tending to occur over the banks and cyclonic (counter-clockwise) circulation around the basins. The northeastern region of the Shelf is the southern limit of winter sea ice in the Atlantic Ocean. The area is unique for having a year-round closure for directed fishing of groundfish established in 1987, located over Emerald and Western Banks. In addition, DFO has declared The Gully region (see Fig 1 ) as a pilot marine protected area. Like several other areas in the northwest Atlantic, the dominant cod fishery collapsed in the early 1990s.

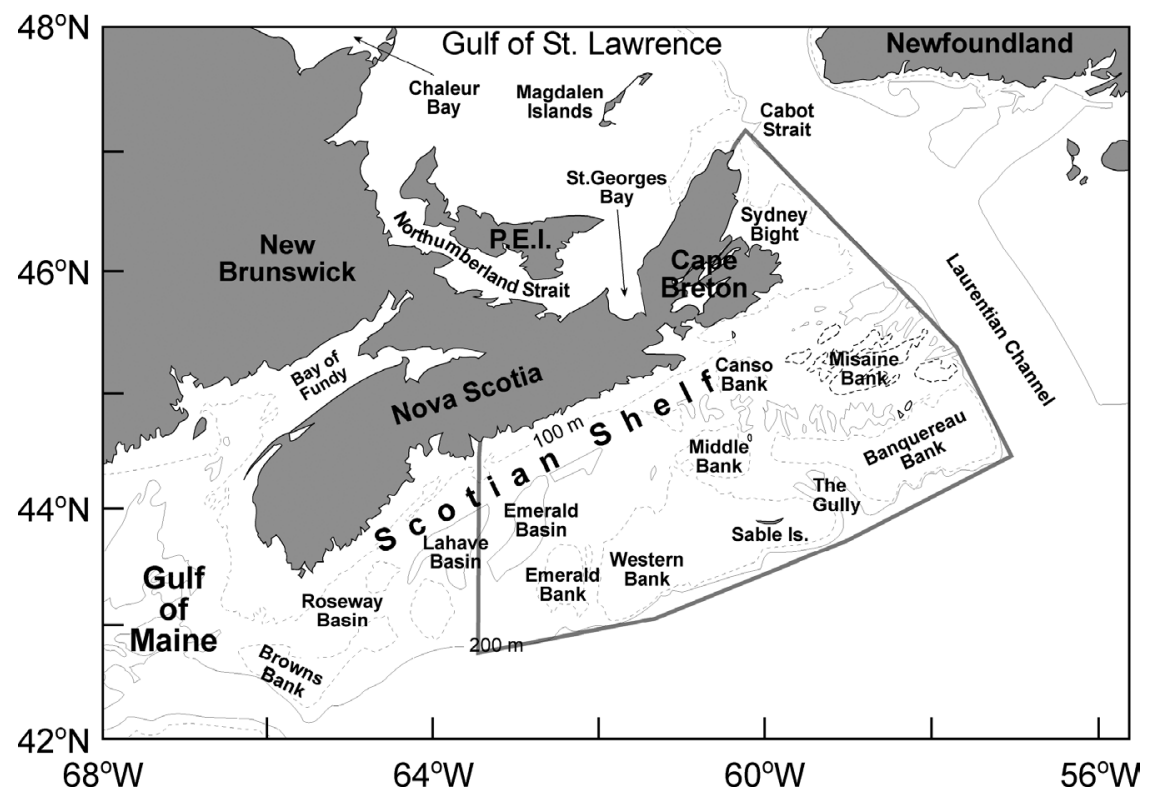

Fig 1 The study area. The line defines the Eastern Scotian Shelf region. No consideration was given to the nearshore zone. 


\section{Data: analysis and integration}

An overall picture of the changes that have taken place on the Eastern Scotian Shelf since 1970 was addressed by adopting an approach similar to the traffic light framework now being applied in stock assessments (i.e. a stepwise application of precautions) and recently used by Link et al. (2002) for an ecosystem evaluation in a fisheries management context of Georges Bank. Time series of sixty-four metrics were used in the evaluation with 50 representing primary indices and 14 indicative of second order indices, i.e. higher level processes such as community composition, ratios of variables or growth. The indices were made directly comparable to one another by expression as anomalies (deviation from long-term mean) in standard deviation units. Colors were used to display the magnitude of the anomalies ranging from strongly negative (below the long-term mean, red) to strongly positive (above the long-term mean, green). The series were ordered using principal components analysis to identify any coherence in their variability over the study period. Thus, the sequence of the indicators reflects the degree of similarity in their temporal dynamics (Fig 2).

\section{RESULTS AND DISCUSSION}

\section{Ecosystem changes}

Seal abundance, pelagic fish abundance, landed value of shellfish, fish species richness and phytoplankton (the continuous plankton recorder (CPR) color index) were among the metrics that changed in a coherent manner relative to those further down the list during the 1970s to the early 1980 s period. These metrics initially had negative values (anomalies). Subsequently, they shifted to positive values in the 1990s where they have remained to the present. Conversely, anomalies of bottom temperatures at Misaine Bank, commercial exploitation levels, groundfish landings and biomass, growth rates of cod, haddock and pollock, average individual fish weight and copepod (Calanus finmarchicus) counts, were positive from the 1970 s to the early $1980 \mathrm{~s}$. In addition to warm bottom temperatures, a weakly-stratified summer water column and a deep mixed-layer depth typified the abiotic conditions at this time. During the 1990s almost all of the positive anomalies for these biotic variables became negative at a time when bottom temperature declined, mixed layer depth decreased and the water column became more stratified. What is visually striking is the change in state from one extreme to the other for almost all the metrics over the study period, with the transition occurring between the years 1985 to 1990 . The changes were systemic and coherent.

The causes of the reciprocal changes in abundance among alternating trophic levels is consistent with the hypothesis of top-down or predator control of food webs - the so-called trophic cascade (Fig 3) (Frank et al. 2005). When the indicators of groundfish abundance were high during the 1970s/mid-1980s, small pelagic fish abundance was low, zooplankton abundance was high and chlorophyll was low. Throughout the 1990s, this pattern 


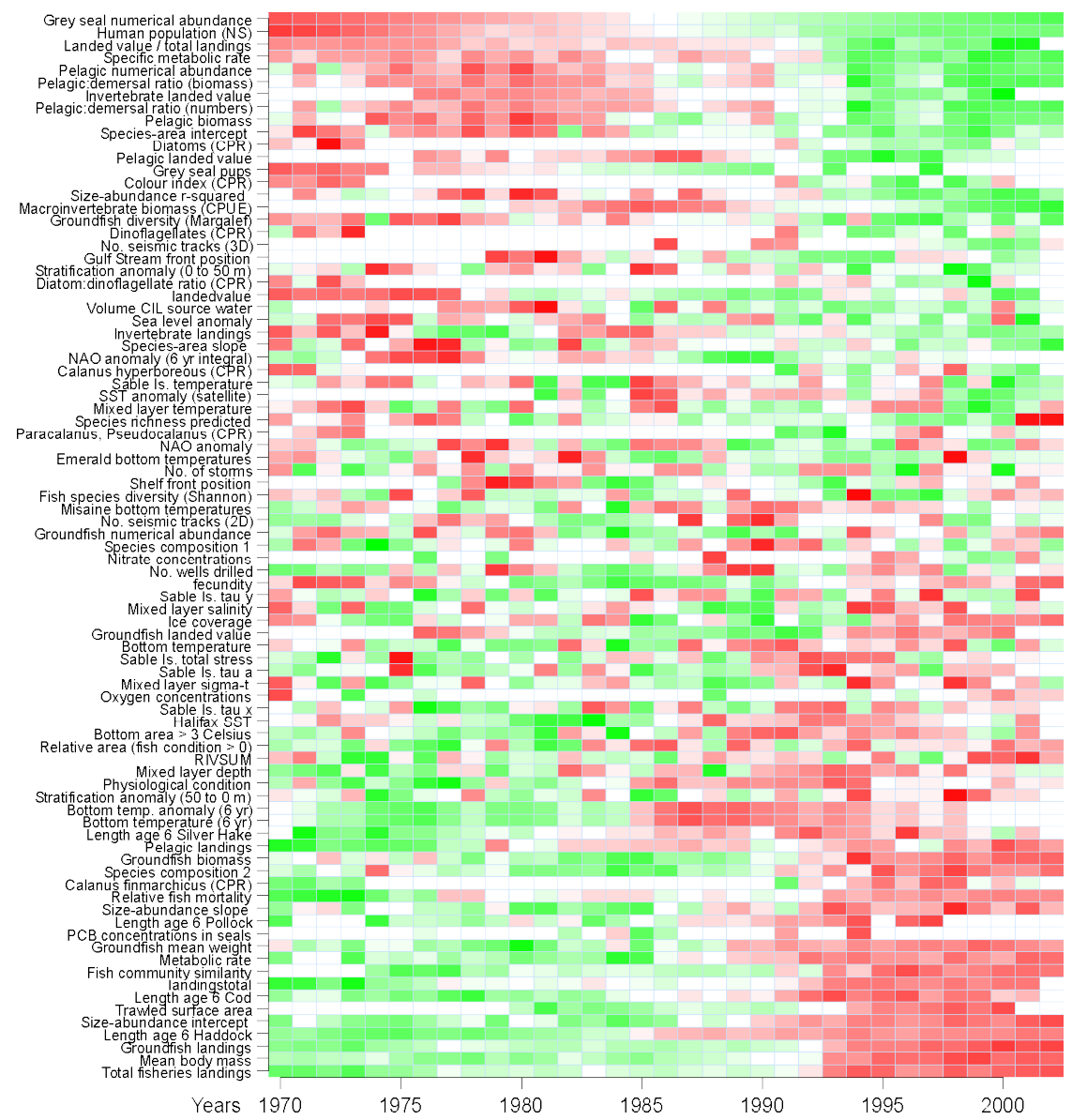

Fig 2 The matrix of time series of annual anomalies of variables considered in the case study and ordered according to their similarity of responses to one another. The ordering was based on a principal components analysis and the visualization reveals a clear shift in the state of the eastern Scotian Shelf ecosystem. Green blocks (cells) indicate above normal conditions, red below normal conditions, and white normal or missing data.

reversed with groundfish abundance low, pelagics high, zooplankton low and phytoplankton high. Changes in ocean climate (described in the next section) have also played a role in the dynamics of the fish community.

Seals have been repeatedly blamed for the changes that have occurred within the groundfish community, most notably the collapse of cod. However, their increases have matched the increases in the pelagic fish community indicating a likely response to large scale ecosystem changes on the Scotian Shelf. In fact, seals may be a moderating influence, reducing the complete dominance of pelagic fish. Furthermore, the proportion of cod in the seal diet has been re-estimated for recent years based on quantitative fatty 

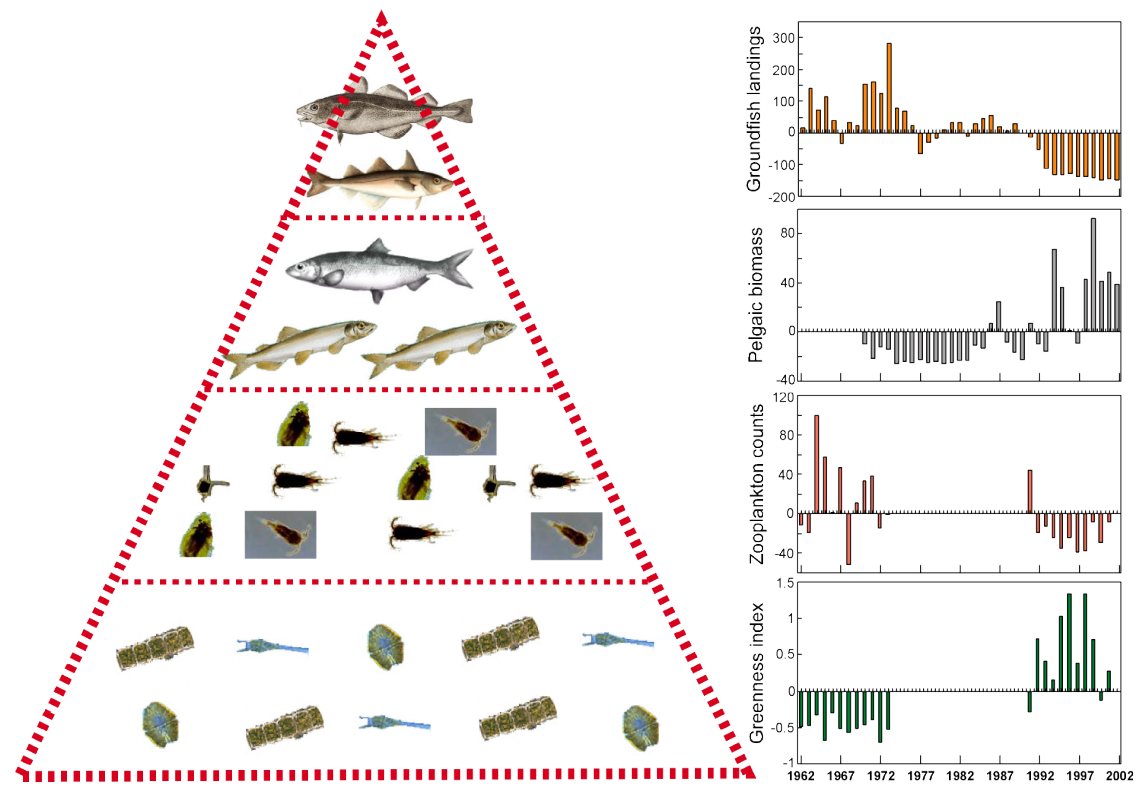

Fig 3 Pictorial representation of a trophic level cascade starting at the top with groundfish, then pelagics to zooplankton, and finally phytoplankton. Time series of annual anomalies of groundfish landings, pelagic biomass, zooplankton counts and CPR colour index, a measure of chlorophyll concentrations.

acid signature analysis (Iverson et al. 2004) and the results indicated that cod is occurring at only trace levels, i.e. less than $1 \%$. Rather, the pelagic species capelin, sandlance and herring are the dominant prey in the diets of grey seals.

Currently, the invertebrate fisheries are extremely lucrative. Their rise in dominance is likely related to the decline in groundfish (their primary predators) as well as changes in the environmental conditions in the area. Invertebrate fisheries associated with lobster, snow crab and northern shrimp maintained and eventually increased revenues for the eastern Scotian Shelf despite the downturn in the traditional groundfish fishery. The temporal change in the average composition of the landings has been seen in several other fisheries systems and has been termed "fishing down the food web". It occurs when the average trophic level of the catch declines over time and the total catch decreases (Pauly et al. 1998). Both conditions are met on the Eastern Scotian Shelf, where the average trophic level (position in the food chain) of the catch of all species was relatively stable until the late 1980s (average of 3.6) and declined to a low of 2.7 in 2000. The total catch from the Eastern Scotian Shelf has also declined from a peak in the early 1970s to a low in the early 1990s (DFO 2003a). A lack of availability of groundfish has been created at the higher trophic levels of the ecosystem, and now the fishery is increasingly targeting species at lower levels in the food web. 


\section{Changes in ocean climate}

Environmental variation has long been known to influence the distribution and abundance of marine organisms. Temperature is well recognized in terms of its effect on growth and maturation of most fish and invertebrate species. The timing of the onset of the spring phytoplankton bloom and its duration, known to be influenced by physical and chemical properties, can influence survival during the early life stages of a variety of species. Variability in circulation patterns can alter larval drift patterns and migration routes. The environment provides a variable setting within which species evolve and adapt. However, many environmental events are unpredictable, such as sudden intrusions of water masses, extreme storms, or long-term changes in temperature or salinity conditions.

During the past two decades, the temperature and salinity conditions of ESS waters have undergone significant changes. Of particular note is the presence of cold subsurface waters (below $50 \mathrm{~m}$ ) in the northeastern region. Temperatures declined through the 1980s and dropped significantly to below normal (relative to the $1971-2000$ mean of $1.73^{\circ} \mathrm{C}$ ) in 1985 (Fig 4). They continued to decline, reaching a minimum in the early 1990s. Temperatures then increased slowly, eventually rising to above normal by the late 1990s. The almost 15-year duration of colder-than-usual temperatures is a significant feature in the over $50^{+}$-year record from the region. The early 1990s were generally the coldest years on record. The principal cause of these cold conditions appears to be along-shelf advection (flow) from both the Gulf of St. Lawrence and off southern Newfoundland, augmented by local atmospherically-induced cooling. Similar cold conditions were ob-
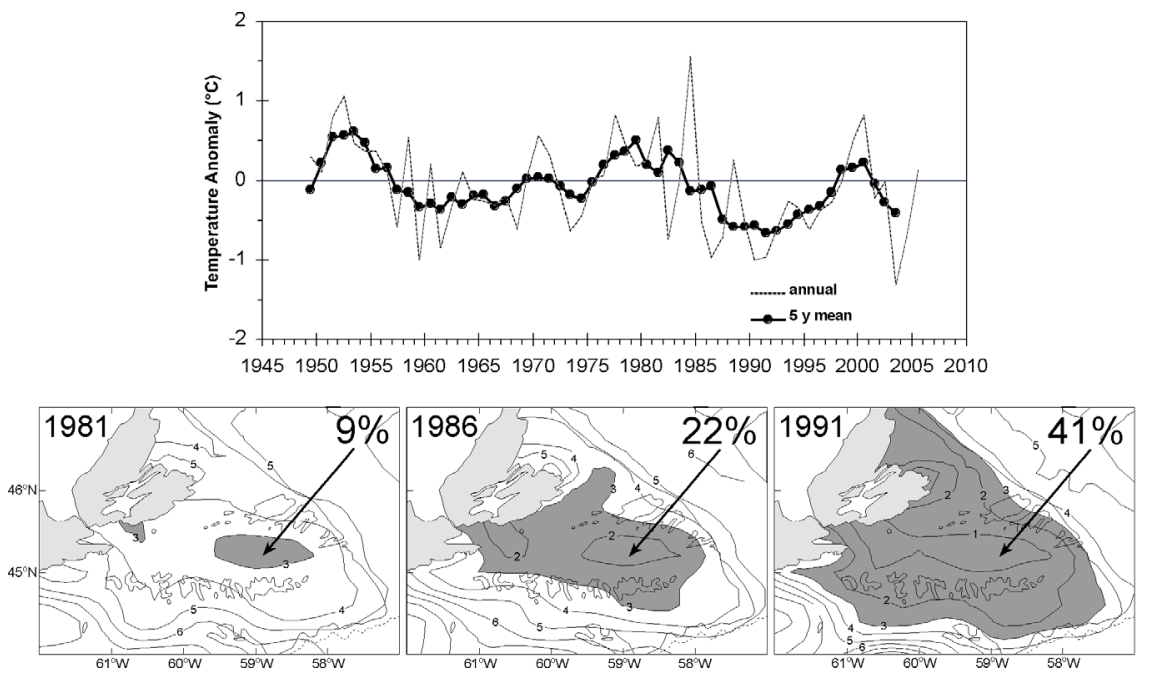

Fig 4 Time series of near bottom temperature at Misaine Bank. Contours of bottom temperatures in selected years $(1981,1986$ and 1991) are shown below. The percentages indicate the amount of bottom area characterized by temperatures less than $3^{\circ} \mathrm{C}$. 
served in the nearshore regions of the Eastern Scotian Shelf but not in the southwestern region of Emerald Basin. There, the influence of the offshore Warm Slope Water moving into the Basin kept subsurface temperatures relatively warm throughout the 1980 s and 1990 s.

In addition to the subsurface changes, there have been important variations in the near surface waters. Foremost among these has been the increase in vertical density gradient, the difference between the density at $50 \mathrm{~m}$ and the surface (Fig 5). It increased to its highest level in the past 50 years over the top $50 \mathrm{~m}$ in the ESS during most of the 1990s. This was principally a result of record low salinities in the near-surface waters that appear to be advected onto the Shelf from the Grand Banks. Reduced storminess, as measured by the variability (standard deviation) in the wind stress at Sable Island may also have contributed to the increasing stratification during at least the first half of the 1990s through reduced vertical mixing. Freshwater discharge into the Gulf of St. Lawrence decreased during the 1990s and

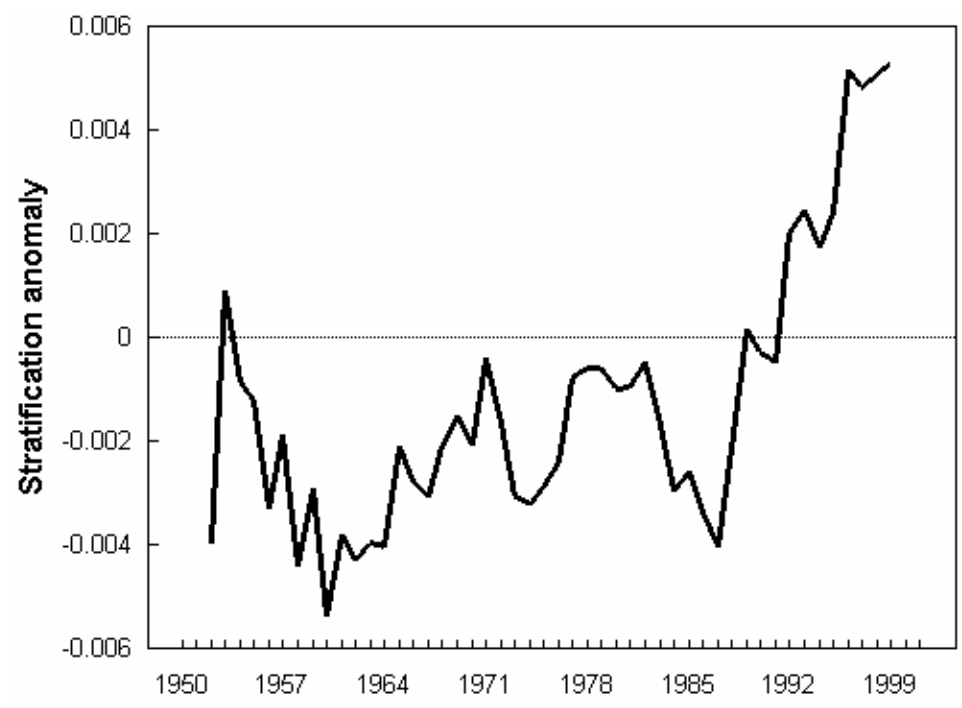

Fig 5 Time series (5 year running mean) of the density difference anomaly divided by $50 \mathrm{~m}$ between $50 \mathrm{~m}$ and the surface for Misaine Bank. The extreme increase in stratification since the late 1980s has not been witnessed before in the data series.

is not expected to have contributed to the lower salinities and increased stratification on the Scotian Shelf. Surface layer temperatures during the period of strong stratification were variable, although satellite data suggest that there were several years of high temperatures in the late 1990s, with the maximum in 1999.

\section{Changes in the fish community}

Profound changes in community composition and body size of groundfish have occurred during the past thirty years on the eastern Scotian Shelf. 
The historical composition of the top five of ten species based on numerical abundance included: redfish, American plaice, silver hake, haddock and cod. This dominance structure has changed dramatically during the past decade and small pelagic species such as sand lance, capelin and herring are now dominant. Only silver hake and haddock have remained major groundfish species since the early 1980s, while cod, redfish, white hake, and thorny skate have decreased. In addition, 10- to 50 -fold increases in the abundance of daubed shanny, turbot, snake blenny and sea poacher were evident in the most recent period relative to 1981-1992. The increasing species are all small-bodied, with the exception of turbot. In addition, temperature conditions appear to influence the occurrence of species new to the area, particularly when conditions remain persistently above or below normal. Several sub-Arctic species were first recorded during the anomalous cooling period that began in the mid-1980s; they include shorthorn sculpin, sea tadpole, Newfoundland eelpout, two horn sculpin, little grubby and checker eelpout. Overall, thirty new species have been captured since 1991, with the vast majority less than $35 \mathrm{~cm}$ long. Conversely, during the warm water conditions that began in the late 1970s several warm temperate/sub-tropical species were captured including beardfish, barracudina, batfish, greeneye, common wolfeel, deepwater flounder and snipe eel (Fig 6).

These temporal changes in fish species composition and abundance suggest that decreases in length and weight averaged across all groundfish species should be evident. The pattern of lowered average body weight was most evident during the 1990s with the largest reduction in the northeastern areas (Fig 7). A similar pattern was observed for fish lengths.

Declining average weight not only reflects increased abundance of smallbodied species, but also contracted size distribution of large-bodied species. For example, adult cod, haddock and pollock (age 5) are now much smaller on average compared to individuals from the 1970s and 1980s. Reductions in size at age are also found in silver hake. The trend of reduced size has occurred despite current low population levels, suggesting that a fundamental, population dynamic process (compensatory growth) is not working among these species.

As a direct consequence of the geometric scaling of numerous physiological, population-dynamic and life-history characteristics with organism size (allometry), there are numerous potential implications of these changes in average body size associated with the formerly large-bodied species of the Eastern Scotian Shelf. The most notable are: shorter generation times, increased natural mortality, increased population variability and decreased bioenergetic efficiencies. For example, direct estimation of natural mortality for cod and haddock was made possible by the closure of the directed fishery and showed levels 2-5 times higher than commonly assumed (DFO 2003b, Mohn \& Simon 2002). Such changes do not necessarily translate to an unhealthy ecosystem but do indicate that it is functioning in a vastly different manner than it has in the past. 


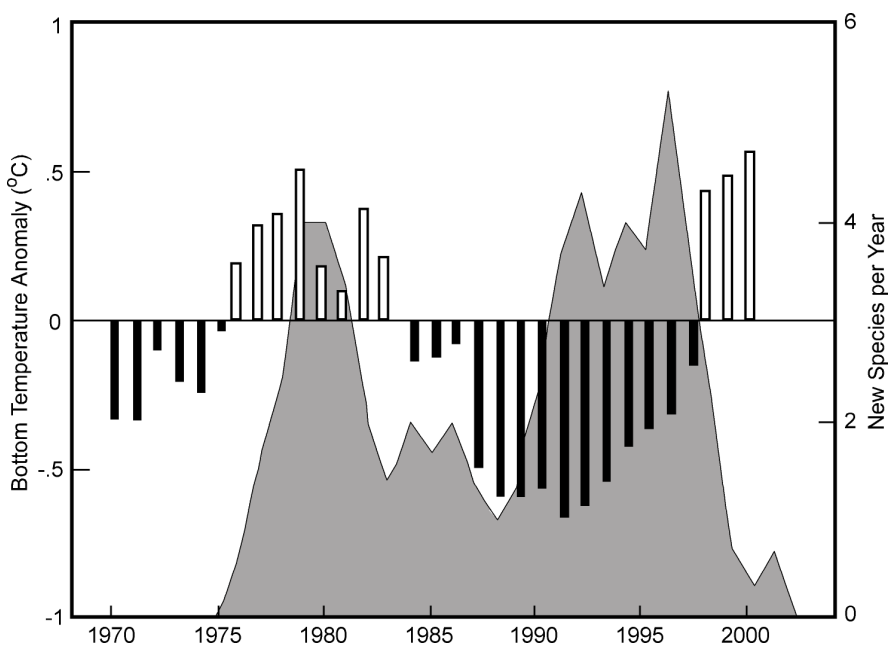

Fig 6 Time series of annual anomalies of bottom temperature at Misaine Bank and the occurrence of fish species new to the eastern Scotian Shelf each year. Note that each peak in the occurrence of species new to the area coincided with either sustained warm or cold bottom waters.
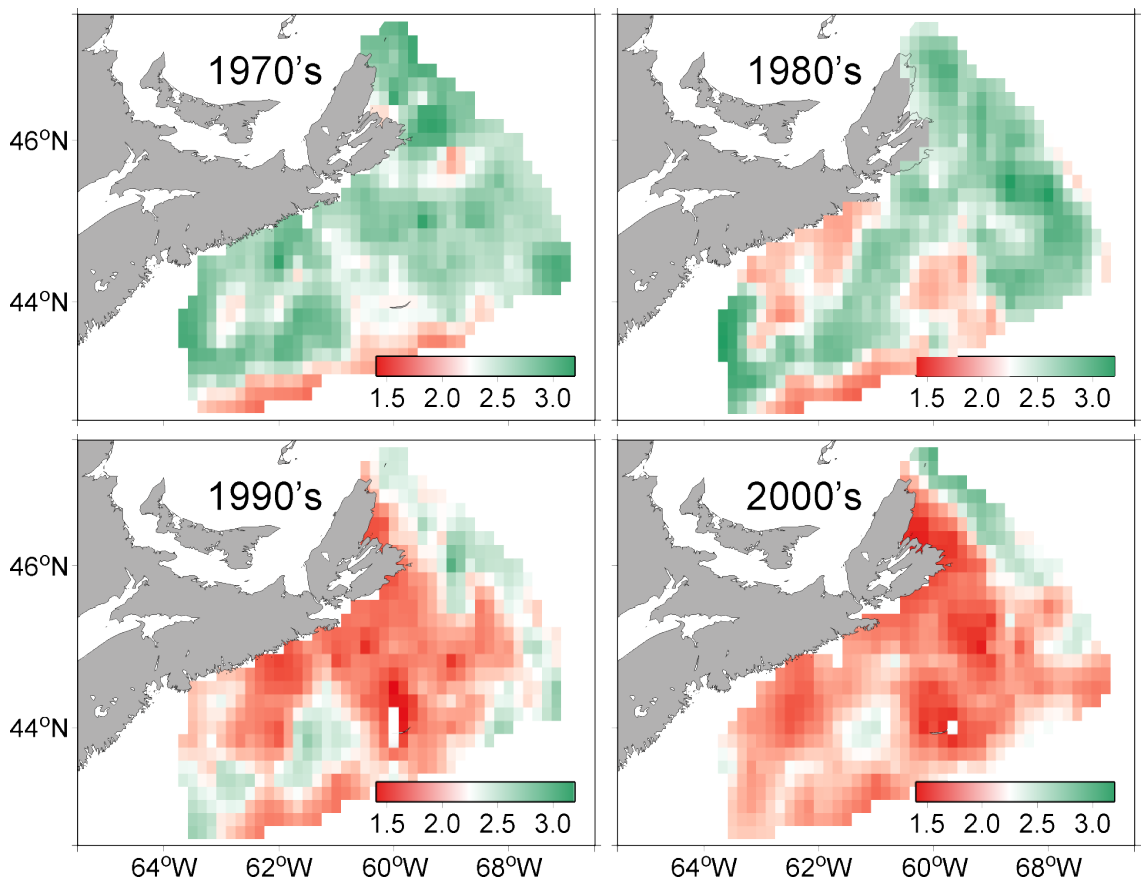

Fig 7 Spatial depiction of the average weight $(\mathrm{kg})$ of groundfish on the Eastern Scotian Shelf for each of three decades (1970s, 1980s, 1990s) and for 2000-02. The trend towards lower average weight is quite striking. 


\section{FUTURE}

\section{What next in the short-term?}

In the near future we plan on estimating system-level "structural" (biomass) and "functional" (metabolic rates, estimated from size-frequency distributions) changes of the fish-component of the entire Scotian Shelf ecosystem. Visualisations of these metrics in a spatial-temporal context and the relative discordance between structure and function will provide a direct estimate of system-level instability of the fish community. Another avenue of research that is being investigated is the use of size-spectral information in the context of "Self-Organized-Criticality" (Bak et al. 1989) to provide another means of evaluating system-level instability. Finally, comparative analyses between other systems that have not shown strong ecosystemic changes (e.g., locations where collapses of major fish stocks have not occurred) are planned to help further understand the causes of these large-scale changes in both ecological structure and function and the potential to identify early warning signs of such hysteresis.

\section{What next in the long-term?}

This comprehensive approach has revealed broad coherent patterns in ecosystem response that would have remained hidden had a single species approach been taken. While examination of single species will continue, the application of multi-species studies incorporating abiotic and human factors will grow. Effort is required to provide better representations of the non-biological driving forces so that they can be more readily incorporated into the fisheries analyses. Contemporaneous evaluations of the resource and environment by geographic area with acknowledgement of interactions between species and their environment is also required to advance the integration of abiotic forcing and ecosystem response. Dynamical connections between driving mechanisms and the fisheries response are needed; it will not be sufficient to connect an environmental variable to fisheries fluctuations simply through a statistical relationship.

It is our hope that comprehensive ecosystem reviews will be undertaken for other geographic areas and that once completed, periodic reviews will be conducted every 4 or 5 years, accompanied by minor annual updates. This will require continued financial commitment to long-term monitoring that is insensitive to short term social, economic and political volatility. In addition, it is important to note that the group that put together the State of the Eastern Scotia Shelf Ecosystem (DFO 2003) report was made up of specialists, some of whom are very highly specialized. Despite this, a valuable study has resulted; specialization alone does not preclude success in a broad study. The means must exist, however, to put the specialists together to address wide-ranging issues. Fortunately, it is not necessary to train generalists, but it helps to have at least some individuals on the team who are more catholic in their outlook. 


\section{REFERENCES}

Bak P, Chen K, Creutz M (1989) Self-organized criticality in the "game of life". Nature 342:780-782

DFO (Department of Fisheries and Oceans) (2003a) State of the eastern Scotian Shelf ecosystem. Ecosystem status report 2003/004

DFO (2003b) Eastern Scotian Shelf cod. DFO Science stock status report 2003/020

Fogarty MJ (2002) Marine ecosystem assessment in a fisheries management context. Can J Fish Aquat Sci 59:1429-1440

Frank KT, Petrie B, Choi JS, Leggett WC (2005) Trophic cascade in a formerly cod-dominated system. Science 308:1621-1623

Iverson SJ, Field C, Bowen WD, Blanchard W (2004) Quantitative fatty acid signature analysis: a new method of estimating predator diets. Ecol Monogr 74:211-235

Lindeman RL (1942) The trophic-dynamics aspect of ecology. Ecology 23:399418

Link JS, Brodzik JKT, Edwards SF, Overholtz WJ, Mountain D, Jossi JW, Smith TD, Fogarty MJ (2002) Marine ecosystem assessment in a fisheries management context. Can J Fish Aquatic Sci 59:1429-1440

Mohn RK, Simon JE (2002) Biological information relevant to the management of 4TVW haddock. CSAS (Canadian Science Advisory Secretariat) Res Doc 2002/102

Odum EP (1968) Energy flow in ecosystems: a historical review. Am Zool 8:1118

Odum EP (1969) The strategy of ecosystem development. Science 164: 262-270

Odum HT (1971) Environment, power and society. John Wiley, New York

Odum HT (1983) Systems ecology: an introduction. Wiley Interscience, New York

Patten BC (1971) Systems analysis and simulation in ecology. Academic Press, New York

Patten BC (1982) Environs: relativistic elementary particles for ecology. Am Nat 119:179-219

Pauly D, Christensen V, Dalsgaard J, Froese R, Torres FC (1998) Fishing down marine food webs. Science 279: 860-863

Regier HA, Henderson HF (1973) Towards an ecological model of fish communities and fisheries. Trans Amer Fish Soc 102:56-72

Regier HA, Kay JJ (1996) A heuristic model of transformations of the aquatic ecosystems of the Great Lakes - St. Lawrence River Basin. J Aquat Ecosys Health 5:3-21

Schindler DW (1990) Experimental perturbations of whole lakes as tests of ecosystem structure and function. Oikos 57:25-41

Sherman K, Skjoldal HR (2002) Large marine ecosystems of the North Atlantic: changing states and sustainability. Elsevier Science, Amsterdam

Steele JH (1985) A comparison of terrestrial and marine ecological systems. Nature 313:355-358

Vollenweider RA (1976) Advances in defining critical loading levels for phosphorus in lake eutrophication. Memorie dell'Istituto Italiano di Idrobiologia 33:53-83 